\title{
Adenomatous Polyposis Coli Is Differentially Distributed in Growth Cones and Modulates Their Steering
}

\author{
Michael P. Koester, ${ }^{1}$ Oliver Müller, ${ }^{2}$ and G. Elisabeth Pollerberg ${ }^{1}$ \\ ${ }^{1}$ Department of Developmental Neurobiology, Institute of Zoology, University of Heidelberg, D-69120 Heidelberg, Germany, and ${ }^{2}$ Max-Planck-Institute for \\ Molecular Physiology, D-44227 Dortmund, Germany
}

Axonal steering reactions depend on the transformation of environmental information into internal, directed structures, which is achieved by differential modulation of the growth cone cytoskeleton; key elements are the microtubules, which are regulated in their dynamics by microtubule-associated proteins (MAPs). We investigated a potential role of the MAP adenomatous polyposis coli (APC) for growing axons, employing embryonic visual system as a model system. APC is concentrated in the distalmost (i.e., growing) region of retinal ganglion cell axons in vivo and in vitro. Within the growth cone, APC is enriched in the central domain; it only partially colocalizes with microtubules. When axons are induced to turn toward a cell or away from a substrate border, APC is present in the protruding and absent from the collapsing growth cone regions, thus indicating the future growth direction of the axon. To assess the functional role of the differential distribution of APC in navigating growth cones, the protein was inactivated via micro-scale chromophore-assisted laser inactivation in one half of the growth cone. If the N-terminal APC region (crucial for its oligomerization) is locally inactivated, the treated growth cone side collapses and the axon turns away. In contrast, if the 20 aa repeats in the middle region of APC (which can negatively regulate its microtubule association) are inactivated, protrusions are formed and the growth cone turns toward. Our data thus demonstrate a crucial role of APC for axon steering attributable to its multifunctional domain structure and differential distribution in the growth cone.

Key words: APC; neuron; axon; growth cone steering; micro-CALI; retina

\section{Introduction}

Adenomatous polyposis coli (APC) was initially identified as a tumor suppressor mutated in colon cancers (Groden et al., 1991). There is increasing evidence that APC is a multifunctional protein with important roles beyond the well described one as an antagonist in the wnt signaling pathway (Näthke, 2004; Hanson and Miller, 2005). The highly conserved, large protein $(310 \mathrm{kDa})$ contains an N-terminal oligomerization domain and binding sites for PDZ (postsynaptic density-93, -95/Discs large/zona occludens-1) proteins, end-binding protein 1 (EB1), tubulin, $\mathrm{mDia}$, axin, $\beta$-catenin, glycogen synthase kinase $3 \beta$ (GSK $3 \beta)$, PP2A (protein phosphatase 2A), Asef (APC-stimulated guanine nucleotide exchange factor), IQ motif-containing GTPaseactivating protein 1 (IQGAP1), and KAP3 (kinesin superfamily-

\footnotetext{
Received 0ct. 31, 2006; revised Sept. 7, 2007; accepted Sept. 18, 2007.

This work was supported by the German Research Council (P0289 and SFB488). We are grateful to R. Brandt (University of Osnabrück, Osnabrück, Germany) for tubulin antibodies and N. Galjart (University of Rotterdam, Rotterdam, The Netherlands) for the EB3 construct. We thankF. Bonhoeffer (Max-Planck-Institute for Developmental Biology, Tübingen, Germany) for substrate stripe assay matrices and D. Jay (Tufts University, Boston, MA) and T. Mack (KeyNeurotek, Magdeburg, Germany) for initiating the micro-CALI system. We are also thankful to H. Avci, C. Hahn, B. Maier, and K. Thelen for support and stimulating discussions, as well as M. Zieher-Lorenz, C. Brandel, and S. Bergmann for excellent technical assistance. We thank U. Engel and C. Ackermann (Nikon Imaging Center, Institute of Zoology, University of Heidelberg, Heidelberg, Germany) for advice with respect to LSM microscopy.

Correspondence should be addressed to $G$. Elisabeth Pollerberg, Department of Developmental Neurobiology, Institute of Zoology, University of Heidelberg, Im Neuenheimer Feld 232, D-69120 Heidelberg, Germany. E-mail: G.E.Pollerberg@urz.uni-heidelberg.de.

D0I:10.1523/JNEUROSCI.2250-07.2007

Copyright $\odot 2007$ Society for Neuroscience $\quad 0270-6474 / 07 / 2712590-11 \$ 15.00 / 0$
}

associated protein 3) (see Fig. 1c). Interacting with these proteins, APC affects proliferation, apoptosis, intracellular signaling, cell adhesion, and migration (Hanson and Miller, 2005). APC binds to and migrates along microtubules accumulating at their plus ends (Mimori-Kiyosue et al., 2000; Kita et al., 2006). APC has been shown in biochemical and cellular assays to increase microtubule stability by enhancing their assembly, promoting their bundling, and protecting them against depolymerization (Munemitsu et al., 1994; Deka et al., 1998; Nakamura et al., 2001; Zumbrunn et al., 2001; Kita et al., 2006).

From fly to man, APC is strongly expressed in the developing and adult nervous system (Bhat et al., 1994); it has been shown to be involved in cell cycle control of neuronal PC12 (pheochromocytoma) cells (Dobashi et al., 1996), apoptosis of neural crest cells (Hasegawa et al., 2002), neurite formation (Dobashi et al., 2000; Haegele et al., 2003), and receptor accumulation in synapses (Matsumine et al., 1996; Temburni et al., 2004). APC has been detected in neurites of neuroblastoma cells (Morrison et al., 1997a), dorsal root ganglion neurons (Zhou et al., 2004), and cortical neurons (Morrison et al., 1997b; Shi et al., 2004; Shimomura et al., 2005; Votin et al., 2005). In growth cones of hippocampal and dorsal root ganglion neurons, APC has been localized at microtubules (Zhou et al., 2004; Votin et al., 2005), key elements transforming environmental information into internal, directed structure that are regulated in their dynamics by microtubule-associated proteins (MAPs) (Dent and Gertler, 2003; Gordon-Weeks, 2004; Baas et al., 2005). 
To elucidate the role of APC for growing axons, we determined its distribution in the developing chick visual system as well as in retinal ganglion cell (RGC) axons and growth cones proceeding freely or induced to turn in vitro. We moreover inactivated APC by micro-scale chromophore-assisted laser inactivation (micro-CALI) in one half of the growth cone: whereas inactivation of the N-terminal oligomerization region, crucial for dimerization, leads to a turn away from the micro-CALI-treated side, inactivation of the 20 aa repeats in the middle region of APC, capable of negatively regulating its microtubule association, causes a turn toward. Our data demonstrate a novel role of APC for navigating growth cones because of its multifunctional domain structure and its differential distribution, which together allow for the local regulation of growth cone dynamics and thus the growth direction of the axon.

\section{Materials and Methods}

Animals. Fertilized white leghorn chicken eggs and adult white leghorn chickens were obtained from a local provider (Körner, Usingen, Germany). Chick embryos and posthatching day 1 (P1) chicks were obtained by incubation of fertilized eggs. All experiments on animals were performed under nationally approved protocols in accordance with the policy on the use of animals in neuroscience research of the Society for Neuroscience.

Protein labeling. Three rabbit sera raised against functional domains of human APC (see Fig. 1c) were used in this study: APC- 85 against the C-terminal region (amino acids 2219-2580) produced in Escherichia coli (Deka et al., 1998) that contains the microtubule binding region, APC-87 (Leroy et al., 2001) against a synthetic peptide representing the first nonphosphorylated 20 aa repeat of the APC middle region (supplemental Fig. 1, available at www.jneurosci.org as supplemental material), and APC-m against the $\mathrm{N}$-terminal region (amino acids 1-250) produced in E. coli that contains the oligomerization domain and two nuclear export signals (Henderson, 2000; Tickenbrock et al., 2002). Immunofluorescence labeling of cryostat sections and cell cultures was performed with all three sera, and no differences in staining patterns were observed; we here show stainings with antibody APC-85, which detects full-length APC (see Figs. 2-4). For Western blots, a mouse monoclonal antibody against APC (amino acids 1-226, Ab-7, clone CC-1; Merck Biosciences, Schwalbach, Germany) was used for comparison. For double staining, antibodies against tubulin (clone DM1A; Sigma, Munich, Germany) and laminin $\beta-2$ chain (clone A5; Millipore, Billerica, MA) were used. All peroxidase- and fluorochrome-conjugated antibodies were purchased from Jackson ImmunoResearch (West Grove, PA), except of the Alexa Fluor-conjugated ones (488 and 546; Invitrogen, Carlsbad, CA). For visualization of EB3 (triple labeling with APC and tubulin), $10 \mu \mathrm{g}$ of EB3-GFP plasmid (Stepanova et al., 2003) were nucleofected (Amaxa, Gaithersburg, MD) into E6 retinal single cells in suspension; cells were then immediately transferred into culture medium and cultured for $2 \mathrm{~d}$.

Retinal cell culture and substrate border assay. Single-cell cultures and explant strips of E6 retina were prepared and stained as described previously (Pollerberg and Mack, 1994; Mack et al., 2000). Extractions were performed as described previously (Black et al., 1994; Hahn et al., 2005). Retina explant strip cultures on zigzag-shaped laminin lanes for the substrate border assays were performed and stained as described previously (Mack et al., 2000; Hahn et al., 2005).

Immunoblots and quantitative analysis. Homogenates of embryonic day 6 (E6) retina were prepared as described previously (Pollerberg and Beck-Sickinger, 1993). Western blots were performed and quantified as described previously (Avci et al., 2004; Hahn et al., 2005); in addition to the high-molecular-weight standard (SDS-6H; Sigma), a monoclonal antibody against MAP1B (clone AA6; Sigma) was used as a $340 \mathrm{kDa}$ marker (Mack et al., 2000). For kinase treatment, Western blots of E6 chick retina homogenates were incubated for $2 \mathrm{~h}$ with GSK3 $\beta(0.25$ $\mu \mathrm{g} / \mathrm{ml})$ and protein kinase A (PKA) $(2 \mu \mathrm{g} / \mathrm{ml}$; a prerequisite for effective GSK3 $\beta$ phosphorylation) or with buffer only (New England Biolabs,
Beverly, MA) basically as described previously (Rubinfeld et al., 1996; Zumbrunn et al., 2001).

Immunohistochemical procedures, microscopy, and quantification. Heads of chick embryos were fixed, sectioned, and stained as described previously (Pollerberg et al., 1985; Zelina et al., 2005). Images were taken using an inverted fluorescence microscope (Axiovert S-100 TV; Zeiss, Göttingen, Germany) equipped with a cooled 3-CCD camera (MC-3215; Sony, Tokyo, Japan) supported by a time base corrector (MPU-F100P; Sony), or an Axiovert 200-M (Zeiss) equipped with a digital camera (AxioCam; Zeiss). Pictures were processed with the Axiovision 4.2 software (Zeiss) and Image J (NIH) and annotated with Adobe Photoshop 7.0 (Adobe Systems, San Jose, CA). High-resolution fluorescence images were performed with a spectral imaging confocal laser-scanning system (C1Si; Nikon Imaging Center, University of Heidelberg) on an inverted microscope (TE 2000-E; Nikon) with $z$-steps of $0.2 \mu \mathrm{m}$. For time-lapse microscopy, glass coverslips (18 $\mathrm{mm}$ diameter) were fitted into plastic Petri dishes and coated as described previously (Mack et al., 2000). The cultures were monitored (Axiovert S-100 TV; at $37^{\circ} \mathrm{C}$ in a humid atmosphere containing $5 \% \mathrm{CO}_{2}$ ); phase-contrast micrographs were taken at 15 s intervals (Axiovision 4.2; Zeiss). Fluorescence quantification of APC in axons was performed basically as described previously (Votin et al., 2005), measuring gray values of a 30 pixel line $10 \mu \mathrm{m}$ distant from the soma (proximal axon) and $10 \mu \mathrm{m}$ rearward from the growth cone neck (distal axon). Data were plotted as means and SEM; significance was assessed using Student's $t$ test.

Micro-CALI of APC in growth cones and quantification. The microCALI setup was built up and used as described previously (Beermann and Jay, 1994; Mack et al., 2000; Wong and Jay, 2000). Micro-CALI ensures spatially limited inactivation (10 $\mu \mathrm{m}$ laser spot diameter) of specific proteins/protein domains in cellular subregions via hydroxyl radicals generated by malachite green isothiocyanate (MITC)-coupled antibodies bound to these proteins (Linden et al., 1992; Liao et al., 1994). IgG fractions of antisera APC-m and APC-87, binding to APC regions distant from the microtubule binding domain, and of nonspecific mouse sera (Sigma) were coupled to MITC (MoBiTec, Göttingen, Germany) as described previously (Buchstaller and Jay, 2000). Lipofection of the MITCcoupled antibodies was performed as described previously (Mack et al., 2000), ensuring unchanged axon elongation and growth cone morphology. Micro-CALI of growth cone subregions was performed basically as described previously (Buchstaller and Jay, 2000; Mack et al., 2000; Diefenbach et al., 2002; Wang et al., 2003): growth cones were monitored for 10 min before micro-CALI for continuous, straight growth without disturbing contacts. Twenty minutes after liposome addition, one half of the growth cone (equal numbers of left and right growth cone sides) was laser irradiated for $2 \mathrm{~min}$; the growth cone behavior was documented for the next $30 \mathrm{~min}$. Axonal turning responses were quantified $5 \mathrm{~min}$ after end of laser treatment, determining the growth direction by fitting a line to the distal axon (50 $\mu \mathrm{m}$, including the growth cone) and measuring the angle between the growth direction before and after laser irradiation. Because axons perform minor lateral deflections as measured in the control experiments applying MITC-IgG $\left(4.6 \pm 1.5^{\circ}\right.$; all angles taken as positive values), a threshold level of $5^{\circ}$ was defined to differentiate between random deflections and induced turning reactions (Mack et al., 2000); plots and quantitative analysis include all angles (also those $<5^{\circ}$ ) measured in the experiments. To measure size changes of the treated and untreated side, the growth cone was bisected by a line fitted to the distal axon (10 $\mu \mathrm{m})$, and the areas covered were determined. Measurements were performed with Image J (NIH), data analysis with Excel (Microsoft, Redmond, WA), and plots with Adobe Photoshop 7.0 (Adobe Systems). Data were plotted as means and SEM. Significance was assessed using MannWhitney $U$ test (angles) and paired Student's $t$ test (areas).

\section{Results \\ Presence of APC correlates with RGC axon extension and navigation}

To analyze APC expression patterns/levels during development of the visual system (Figs. 1,2), we used polyclonal antibodies raised against the $\mathrm{C}$-terminal domain (APC-85), the middle 20 aa 
repeat domain (APC-87), and the N-terminal domain (APC-m) of human APC, which have identities/similarities to the corresponding chick sequences of $84 /$ $88 \%, 100 / 100 \%$, and $93 / 97 \%$, respectively (supplemental Fig. 1, available at www. jneurosci.org as supplemental material). Western blot analysis shows that all three sera specifically recognize the $310 \mathrm{kDa}$ APC band in homogenates of E6 chick retina (Fig. 1a). Binding of antibody APC-87, which was generated against the peptide representing the (nonphosphorylated) first 20 aa repeat, to APC is completely abolished by pretreatment of the Westernblotted retina homogenate with kinases GSK3 $\beta$ and PKA, demonstrating that antibody APC- 87 selectively binds to the 20 aa repeat $(s)$ in the nonphosphorylated state (Fig. $1 b, c)$. Moreover, ELISA studies reveal that antibody APC-87 binds with equal affinity to the first repeat as to the third (half-maximal binding to both at the same dilution of $1: 1.3 \times 10^{5}$ ) (supplemental Fig. $1 a-c$, available at www. jneurosci.org as supplemental material). Because the third repeat is the one with the lowest similarity to the first repeat $(75 \%)$, the equal affinity of antibody APC-87 to both peptides indicates that this serum binds to all seven repeats with similar efficiency. Moreover, preincubation of antibody APC-87 with the peptide representing the third repeat completely abolishes its binding to APC (supplemental Fig. $1 d$, available at www.jneurosci.org as supplemental material), indicating that basically all antibodies in the serum bind to this repeat and thus can be concluded to bind to all seven repeats.

The changing levels of the APC protein during development were determined by quantitative Western blot analysis of retina homogenates of various stages from E4 to adult (Fig. 1d). APC is present at high levels already in the earliest phase of RGC axon formation (E4) and is maintained at this level for the next $2 \mathrm{~d}$ when RGC axon extension in the retina reaches its maximum (E6). From then on, with increasing numbers of RGC axons (i.e., their distal ends) leaving the retina (E8-E10), levels of APC in the retina decrease to approximately one-sixth. When all axons have left the developing retina (E12-E18), APC is no longer detectable here. Thus, occurrence of APC in the developing retina is clearly correlated to the presence of extending RGC axon tips, indicating a specific role of APC for axonal growth/navigation. The minor reexpression at the first day after hatching $(\mathrm{P} 1)$ points to a further function of APC in later phases of retinal maturation.

To correlate expression levels detected by Western blot analysis to the distribution patterns of APC in cellular compartments and cell types during development, sections of the visual system were immunolabeled (Fig. 2). Early in retinal development (E3), APC is already present in the first RGC somata of the (central) retina, which have completed their radial migration from the ventricular side, forming the ganglion cell layer (Fig. 2a). APC is also found in a few cells located in the neuroepithelial cell layer and at the ventricular side of the retina, most likely representing RGCs migrating toward the ganglion cell layer or at the onset of this migration (see below). The high levels of APC found in the early embryonic retina by Western blot analysis can thus be at-
C

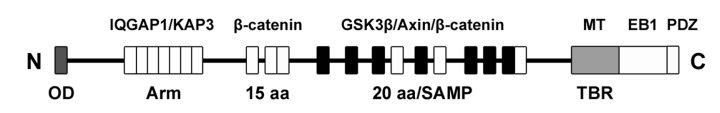

d
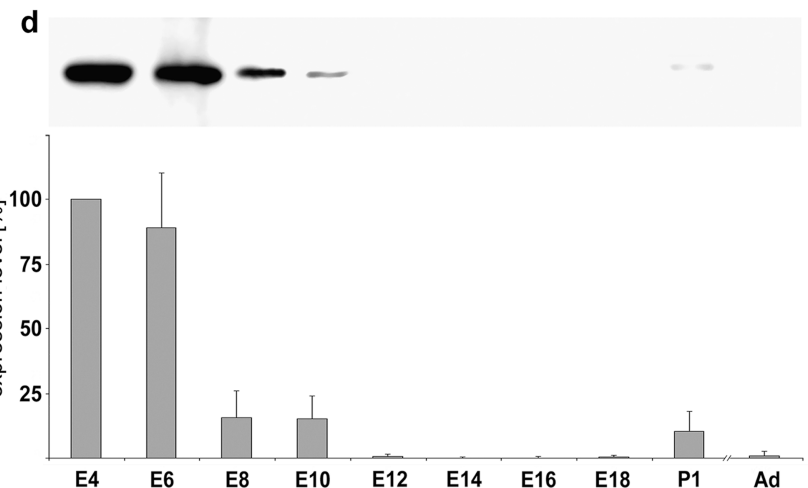

Figure 1. APC expression during retinal development. $\boldsymbol{a}$, In Western blots of E6 chick retina homogenates, polyclonal antibodSchematic representation of APC depicts its functionally characterized domains including the oligomerization domain $(0 \mathrm{D}$; dark grepeats (black), and the microtubule (MT) binding site (TBR; light gray). $\boldsymbol{d}$, Quantitative densitometric E4 to adult (Ad) APC is already present at highlevels in the early retina (E4-E6) decreases to $~ 17 \%$ in the next $2 \mathrm{~d}$ (E8 $-\mathrm{E} 10$ ), and further to undetectable levels in the following days (E12-E18). A minor reexpression appears at the first day after hatching (P1). Histogram represents means obtained from three independent experiments. The signal detected at E4 is set to $100 \%$. Error bars

tributed to differentiating RGCs. At E6, all RGCs in the central retina have sent out axons, which form the optic fiber layer (OFL); these axons contain high concentrations of APC, whereas the RGC somata display only moderate levels, pointing to an axon-specific function of APC. At this stage, the RGC migration has come to an end (in the central retina), and the neuroepithelial layer is now free of APC-positive cells. Three days later, when the distal ends of the central RGC axons have left the retina (E9), the OFL is almost devoid of APC; only a thin band of APC-positive RGC axons that strictly neighbors the vitreous is still present in the OFL. This band contains the growing tips of RGC axons still emerging from the peripheral retina. Hence, also at E9, APC is concentrated at the extending distal axon end and is absent from the proximal (i.e., more mature) axon region. Moderate APC levels in RGC somata are still maintained, also in the RGCs of the central retina, which carry axons already devoid of APC (in their retinal section), pointing to an ongoing somatic APC production (see below). At E12, when all distal axon ends have left the retina, hardly any APC can be detected here, in accordance with the Western blot data. A weak expression is present in the outer nuclear layer, where the prospective photoreceptor cells become postmitotic and differentiate as the second cell type after the RGCs, pointing to a role of APC in process formation also for these neurons.

We next analyzed the APC distribution of RGC axons on their entire pathway to the tectum opticum of the mesencephalon. At E6, highest APC levels are found in the optic nerve colonized by the RGC axons extending from the central retina (Fig. 2b). The distal parts of the youngest RGC axons, which are located in the ventral marginal region of the optic nerve, are strongest positive for APC, as already observed in the OFL of the developing retina. At E9, when most RGC axon tips have already passed through the optic nerve, APC levels are clearly decreased in this structure now 

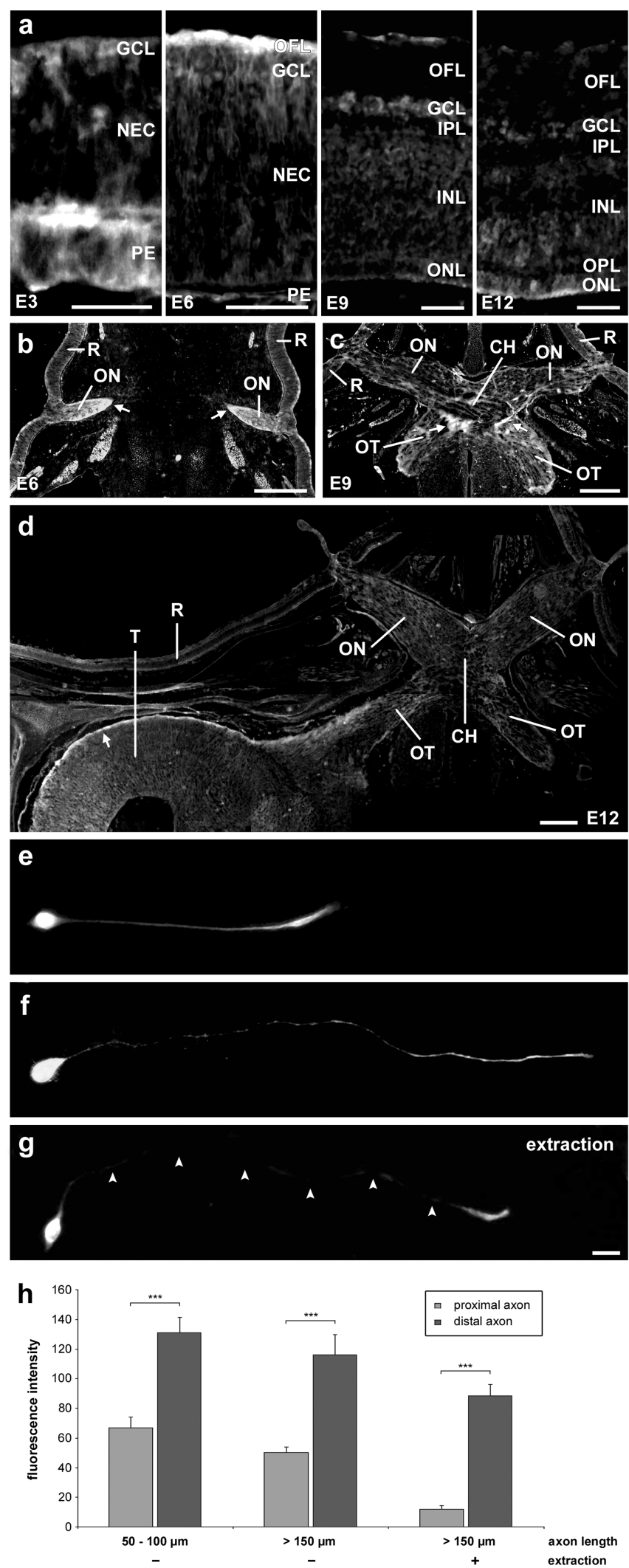

Figure 2. Distribution patterns of APC in developing axons. $\boldsymbol{a}$, Immunofluorescence labeling of cryostat sections shows that at $\mathrm{E} 3 \mathrm{APC}$ is present in the forming ganglion cell layer $(\mathrm{GCL})$ at the vitreous side of the central retina (top) composed of RGC somata, in a few cells located in the neuroepithelial cell (NEC) layer, at the ventricular side of the retina, and in the pigment epithelium (PE). At E6, APC is strongest in optic fiber layer (OFL) and only moderately present in RGC somata. At E9, the OFL is almost devoid of APC except for a thin band at its vitreous side; RGC somata still display moderate APC levels. AtE12, APC is hardly detectable in the retina, including the forming inner plexiform layer (IPL), inner nuclear layer (INL), and outer plexiform layer containing middle axon sections (Fig. 2c; supplemental Fig. 2, available at www.jneurosci.org as supplemental material). At this stage, the highest APC signal is found in the ventral chiasm and at the entrance to the optic tract, i.e., again in the regions containing the youngest growing distal RGC axons at this stage (Thanos and Mey, 2001). At E12, the APC concentration has moved further forward into the posterior-lateral part of the tectum opticum and is now found most heavily in the (anterior-ventral) stratum opticum, i.e., in the layer of the tectum opticum that is solely composed of distal RGC axons (Fig. $2 d$ ). Thus, the moderate APC levels found at E9 in RGC somata but not on their proximal axons (in the OFL) can be attributed to the still-ongoing production of APC, which is transported to the distal axon regions outside of the retina. At E12, when the axons of these central RGCs reach the tectum and extension comes to an end, APC disappears from their somata.

To visualize the subcellular distribution of APC along the RGC axon, immunolabeling of sparse single-cell cultures of E6 retina was performed. In short (i.e., young) axons (50-100 $\mu \mathrm{m})$, APC is present over their entire length with enrichment in the distalmost region next to the growth cone (Fig. 2e). Quantification of the APC immunofluorescence signal (Fig. $2 h$ ) reveals almost double levels of distal APC $(214 \pm 27 \% ; p \leq 0.00007 ; n=$ $10)$ compared with proximal. In longer (i.e., more mature) axons $(>150 \mu \mathrm{m})$, the APC accumulation rate $(237 \pm 28 \% ; p \leq$ $0.0002 ; n=10)$ is not significantly $(p \leq 0.55)$ changed (Fig. $2 f$ ). The APC-enriched distal region stays about constant with respect to length $(50 \mu \mathrm{m})$ and degree of enrichment (approximately double), independent of the total axon length (up to $600 \mu \mathrm{m}$ observed; data not shown); this region corresponds to the youngest part of the axon, formed in approximately the last $20 \mathrm{~min}$ before fixation (growth rate, $\sim 3 \mu \mathrm{m} / \mathrm{min}$ ). These in vitro findings thus correlate well with the in vivo distribution patterns where the highest concentration of APC is always present in the most distal (i.e., youngest) region of growing RGC axons. APC in the proximal axon is highly susceptible to detergent extraction, whereas in the distal axon only insignificant amounts are extracted (Fig. $2 g$ ), resulting in a significantly ( $p \leq 0.0086)$ increased difference with approximately 10 -fold higher APC levels distal (1120 $\pm 198 \%$; $\left.p \leq 10^{-8} ; n=10\right)$ than proximal. This indicates the presence of a substantial pool of extractable (i.e., nonanchored) APC in the proximal axon; in contrast, distal APC appears to be tightly held (e.g., by cytoskeletal structures); interestingly, APC colocalizes with the dynamic (tyrosinated) microtubule population, which is also enriched in the distal axon (supplemental Fig. 3, available at www.jneurosci.org as supplemental material).

Our data show that APC is expressed by RGCs from very early

$\leftarrow$

(OPL); the outer nuclear layer (ONL) shows a weak APC signal. Sections of the entire visual system show the distribution of APC from retina to tectum. $\boldsymbol{b}$, At E6, APC levels are high in the optic nerve $(0 \mathrm{~N})$, where the growing $\mathrm{RGC}$ axon regions are located in the ventral, typically crescent-shaped region (arrows). c, At E9, the strongest APC signal is in the ventral regions of the chiasm ( $\mathrm{CH}$; arrows) and at the beginning of the optic tract (OT) containing the distal RGC axons (supplemental Fig. 2, available at www.jneurosci.org as supplemental material). $\boldsymbol{d}$, At E12, APC is strongest in the stratum opticum (arrow) of the tectum (T; R, retina) and the ventrolateral $0 \mathrm{~T}$, both composed of growing RGC axon regions. $\boldsymbol{e}$, Immunostaining of E6 retinal single-cell cultures shows that in short axons, APC is present over the entire length with a distal enrichment. $\boldsymbol{f}$, In longer axons, APC is predominately present at the distal axon. $\boldsymbol{g}$, After extraction, APC remains only in the distal axon (arrowheads delineating axon). $\boldsymbol{h}$, Quantification of $A P C$ immunofluorescence intensity (mean gray values, arbitrary units) of young, mature, and extracted (mature) RGC axons in vitro. Error bars represent SEM. $n=10$ each. ${ }^{* * *} p \leq 0.001$. Scale bars: $\boldsymbol{a}, 50 \mu \mathrm{m} ; \boldsymbol{b}-\boldsymbol{d}, 500 \mu \mathrm{m} ; \boldsymbol{e}-\boldsymbol{g}, 10 \mu \mathrm{m}$. 
differentiation on; in the soma, APC continuously decreases and disappears when the axon has reached its target, the mesencephalon. In contrast, APC is robustly concentrated in the distal RGC axon throughout its entire pathway in vivo and also in vitro. Together, these findings indicate that APC plays a role specifically for axon extension/navigation.

\section{APC is differentially enriched at microtubule populations in the growth cone}

To obtain insight into a potential role of APC in axonal steering, its distribution in growth cones of RGC axons extending in retinal single-cell cultures was analyzed. APC is enriched in the central growth cone domain where total tubulin (the entire population of tubulin) is also concentrated; the detailed staining patterns, however, are not identical. Selective labeling of microtubule subpopulations reveals that APC is located behind the youngest, tyrosinated microtubules and in front of the more mature, acetylated ones (for double staining and quantifications, see supplemental Fig. 4, available at www. jneurosci.org as supplemental material). Confocal laser-scanning microscopy visualizes the distribution of APC throughout the growth cone from the basal, substrateattached ("ventral") side to the upper ("dorsal") side (Fig. 3). APC appears in discrete round clusters with a diameter of $0.25 \pm 0.03 \mu \mathrm{m}(n=10)$, which corresponds to the cluster size observed in epithelial cells (Reilein and Nelson, 2005). The APC clusters are mostly associated with microtubules but also found independently, in particular in the peripheral domain. APC and microtubules show a low degree of colocalization in the dorsal region of the growth cone (Fig. 3a), whereas APC displays a high correlation to the microtubule distribution pattern in the ventral region close to the substrate where microtubule slowing down/docking/capturing can take place (Fig. $3 b$ ). In accordance, APC is most prominently enriched at those microtubules ends terminating at the plasma membrane (at filopodial tips and lamellipodial margin) and not at those with free space ahead of them (within the central and peripheral domain) (Fig. 3c), pointing to APC accumulating stronger at slowing/stopping microtubule plus ends than at growing microtubule plus ends. To correlate the APC accumulations with microtubule growth, we performed double and triple labeling of APC and tubulin with GFPEB3, a specific marker for polymerizing
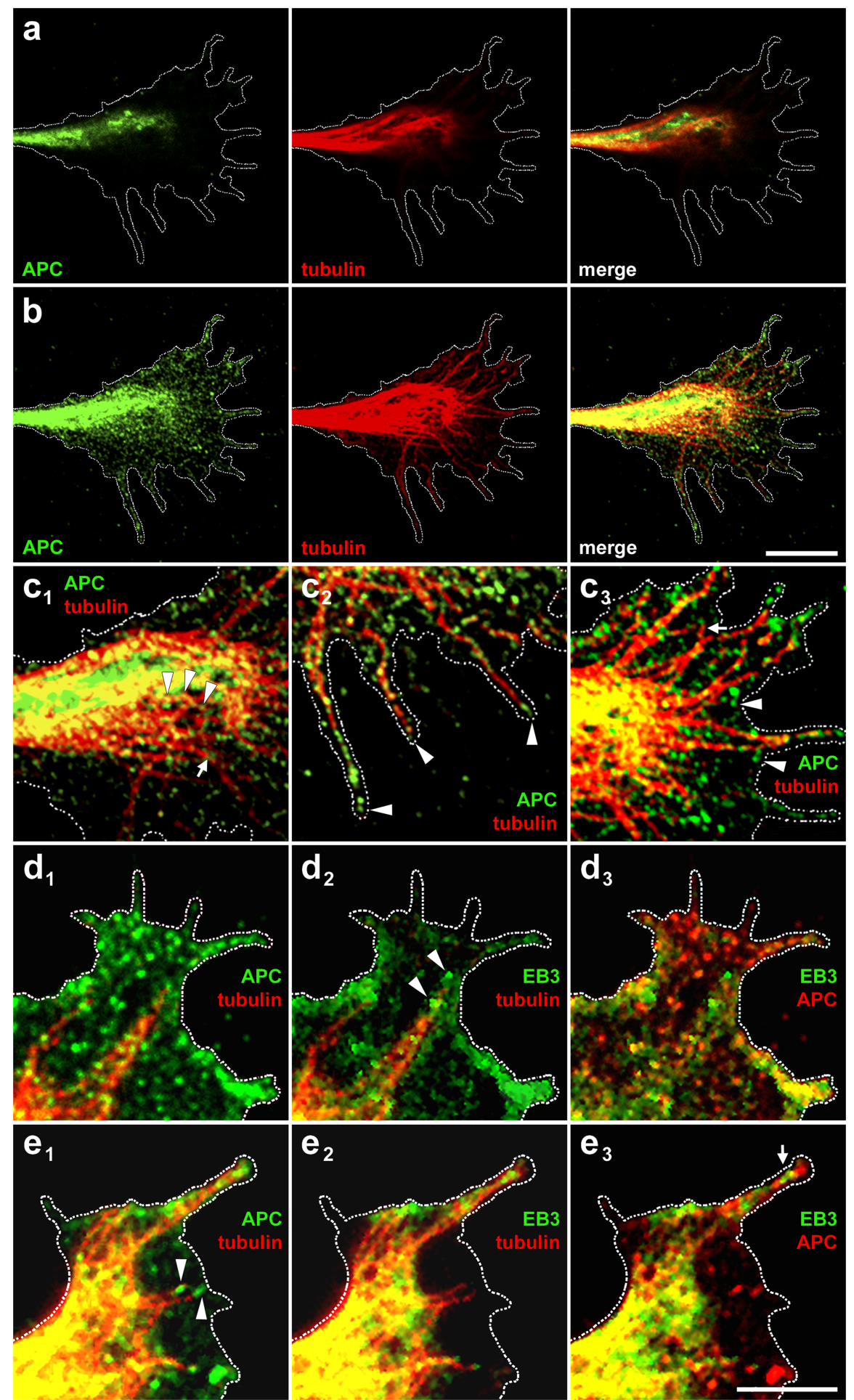

Figure 3. Distribution of APC and microtubules in RGC growth cones. $\boldsymbol{a}$, Laser-scanning microscopy reveals that APC and microtubules hardly colocalize in the dorsal region of the growth cone. $\boldsymbol{b}$, In the substrate-attached ventral growth cone region ( $400 \mathrm{~nm}$ beneath $\boldsymbol{a}$ ), APC and microtubules colocalize to a high degree. $\boldsymbol{c}$, Higher magnifications of the ventral growth cone show the decoration of microtubules with APC clusters (arrowheads) in the central domain $\left(\boldsymbol{c}_{\mathbf{1}}\right)$; microtubules hardly decorated with APC (arrow) do not terminate in the central domain but extend into the periphery. In filopodia $\left(\boldsymbol{c}_{2}\right), A P C$ is enriched at the ends of most microtubules (arrowheads). In the peripheral domain $\left(\boldsymbol{c}_{3}\right)$, it is visible that APC also occurs independently of microtubules (arrowheads); microtubule ends that have not yet reached the plasma membrane (arrow) are hardly decorated by APC. $\boldsymbol{d}$, Such free microtubules $\left(\boldsymbol{d}_{\mathbf{1}}\right)$ show the typical EB3 comets $\left(\boldsymbol{d}_{\mathbf{2}}\right)$ at their plus ends (arrowheads), which are free of APC accumulations $\left(\boldsymbol{d}_{3}\right) . \boldsymbol{e}, \mathrm{APC}$ is accumulated at microtubule tips in perpendicular apposition (arrowheads) to the plasma membrane $\left(\boldsymbol{e}_{\boldsymbol{1}}\right)$, whereas EB3 is absent from such microtubules $\left(\boldsymbol{e}_{2}\right)$ with the exception of a filopodium (arrow) where EB3 cannot diffuse away efficiently $\left(\mathbf{e}_{3}\right)$. Note that microtubules in parallel apposition to the lateral growth cone margin (upper left) carry EB3 (i.e., are growing) but no APC accumulation. Dashed line depicts ventral growth cone perimeter. Entire growth cones as merged pictures and single channels are shown for $\boldsymbol{d}$ and $\boldsymbol{e}$ in supplemental Figure 6 , available at www.jneurosci.org as supplemental material. Scale bars: $\boldsymbol{a}, \boldsymbol{b}, 10 \mu \mathrm{m} ; \boldsymbol{c}-\boldsymbol{e}, 5 \mu \mathrm{m}$. 

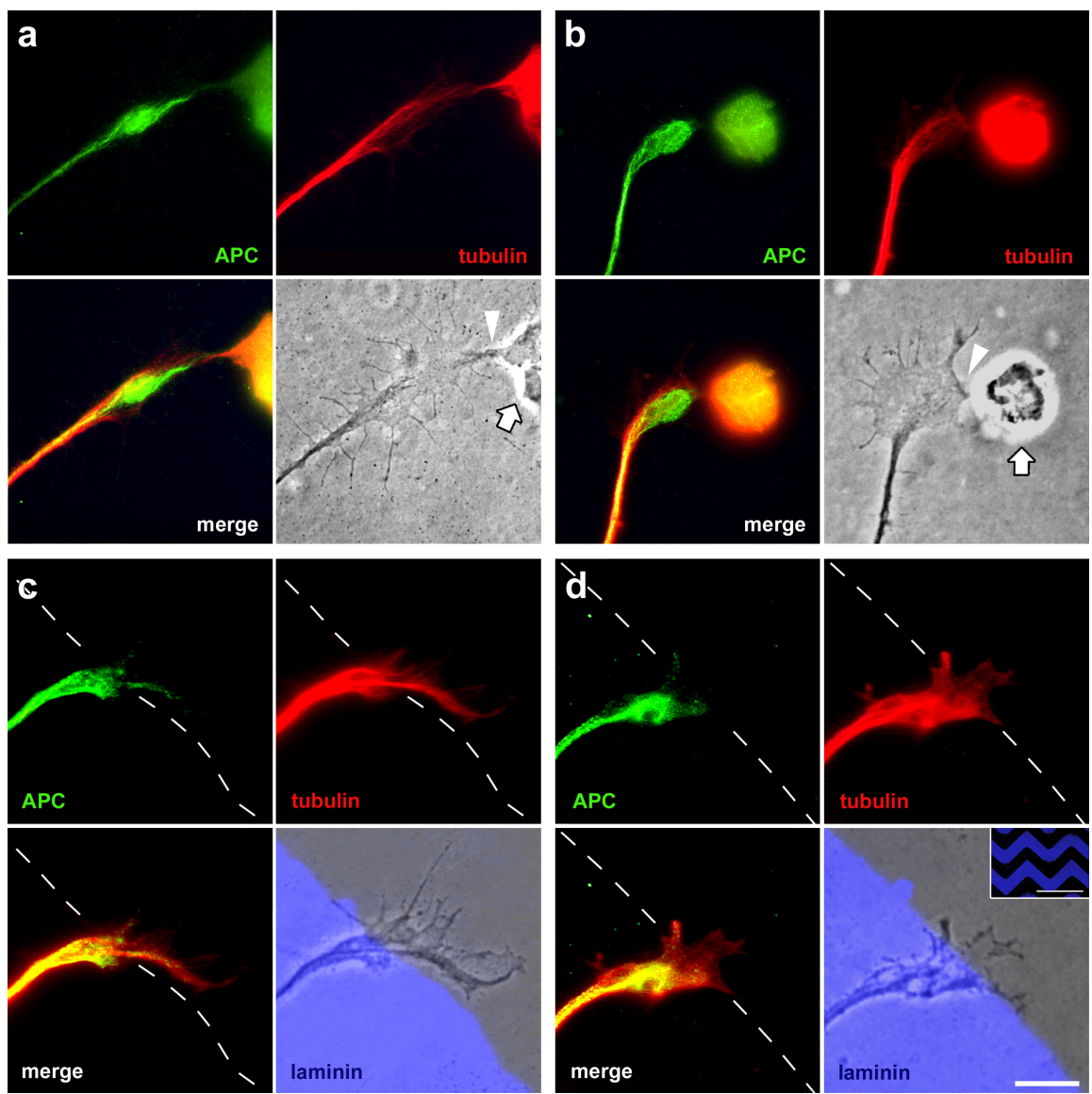

Figure 4. Distribution of APC in turning growth cones. $\boldsymbol{a}, \boldsymbol{b}$, In E6 retinal single-cell cultures, double-immunofluorescence labeling shows that growth cones turning toward a live, phase-contrast bright cell (arrows) display an APC accumulation in the region forming the cell contact (arrowheads), whereas microtubules are rather located on the other side of the APC accumulation. $\boldsymbol{c}, \boldsymbol{d}$, Two examples of triple immunofluorescence-labeled growth cones of RGC axons repulsed at borders of zigzag-shaped substrate lanes (depicted in the inset in $\boldsymbol{d}$ ). APC is hardly present in the growth cone region on the low-laminin lane (with the exception of a narrow strip along the substrate border) and enriched in the portion on the high-laminin lane, thus indicating the future growth direction. Tubulin is present in both parts of the growth cone, it is at lower levels in the one that is to be retracted. For two more examples, see supplemental Figure 7, available at www.jneurosci.org as supplemental material. The merged phase-contrast and laminin fluorescence micrographs are shown in the lower right panels. Scale bars: $10 \mu \mathrm{m}$; inset, $500 \mu \mathrm{m}$.

microtubule plus ends. Microtubule plus ends, which have not yet reached the plasma membrane, are clearly decorated with EB3 comets (i.e., are extending) and lack prominent APC accumulations (Fig. 3d). In contrast, microtubule tips in perpendicular apposition to the plasma membrane at the growth cone margin do not display EB3 decorations (i.e., do not grow), but exhibit strong APC accumulations (Fig. 3e). Moreover, APC and EB3 largely colocalize in the ventral growth cone, where microtubules can be slowed/docked; in the dorsal growth cone, in contrast, the bulk of APC stays behind EB3, again indicating that APC accumulates at stopping rather than at growing microtubule plus ends (supplemental Fig. 5a,b, available at www.jneurosci.org as supplemental material). Double labeling of APC and actin filaments reveals a largely independent distribution except beyond for the margin of the plasma membrane where APC could interact with the cortical cytoskeleton actin; in contrast, APC exhibits an excellent colocalization with neurofilament 200, which might indicate an association of APC to these filaments (supplemental Fig. $5 c, d$, available at www.jneurosci.org as supplemental material).

The experiments show that APC is enriched in the central growth cone domain and found behind the youngest and ahead of the more mature microtubules; APC selectively accumulates at microtubule plus ends terminating at the plasma membrane and not on growing ones. Together, the findings indicate that in growth cones APC might play a role in the differential, local regulation of microtubule dynamics.

\section{Local accumulation of APC in growth} cones predicts the new growth direction To get first insight into the role of APC during steering reactions, its distribution in turning growth cones attracted by (live) retinal cells or repulsed by substrate borders was analyzed (Fig. 4). In single-cell cultures of E6 retina, proceeding RGC axons turn toward other retinal cells, their growth cones extending long-lived protrusions to contact them extensively as seen in time-lapse analysis (data not shown). Double-immunofluorescence staining reveals that these growth cones display a differential distribution of APC and tubulin: the APC distribution extends from the central domain of the growth cone into the tip, which forms the initial cell-cell contact (Fig. 4a), which is in contrast to freely proceeding growth cones, in which APC is concentrated in the central domain (Fig. 3; supplemental Fig. 4). Also, growth cones in more intimate cell contact show APC extending toward the cell contact side, in the case of a lateral contact resulting in a clearly eccentric distribution (Fig. 4b). The microtubules, in contrast, are located lateral to the APC accumulation, opposite to the cell contact side. In all investigated growth cones turning toward a cell (positive turn; $n=15$ ), the APC enrichment extends further into the contact side and is more focused toward the cell than the bulk of the microtubules, which only penetrate into the contacting growth cone region to a moderate degree.

To investigate the distribution of APC in growth cones performing a negative turn, we used an in vitro assay in which a defined change in growth direction is induced at substrate borders. Challenged by a low-laminin lane, all RGC axons turn away and continue to grow on the high-laminin lane; for this, the growth cone region extending on the low-laminin lane is retracted, whereas the part on the high-laminin is maintained and transformed into an axon. Immunofluorescence labeling of APC and tubulin (Fig. 4c,d) shows that microtubules are present in both growth cone regions. APC, in contrast, is almost completely restricted to the growth cone region that is maintained, the relative position of the APC accumulation in the growth cone indicating the new growth direction of the axon (along the substrate border on the preferred substrate). Only minimal amounts of APC are present in the growth cone region on the avoided substrate. In these axons (negative turn; $n=20$ ), APC is always located more rearward than the microtubules, which is in clear contrast to positive turns, in which APC is found in front of the microtubules. The same APC distribution as detected in the substrate border assay is found when axons turn away from cell debris $(n=79)$ (supplemental Fig. 7a,b, available at www.jneurosci.org as sup- 
plemental material), indicating independency of the nature of the cue.

The data show that in growth cones induced to turn, high concentrations of APC are present in maintained regions and absent from regions that are to be retracted. The localization of APC relative to the microtubules predicts the differential extension/retraction of growth cone parts and thus the future growth direction of the axon. The differential distribution of APC in steering growth cones might thus contribute to axonal navigation via local regulation of microtubule dynamics.

\section{Local inactivation of APC domains in} the growth cone regulates axon steering To investigate the functional role of the differential APC distribution in proceeding growth cones, we locally inactivated this protein in one growth cone side by micro-CALI (Fig. 5). For this, MITCcoupled APC antibodies were lipofected into RGC axons; the left or right side of the growth cone was laser irradiated, inactivating the targeted region of the APC molecule; and the axonal reactions were monitored by time-lapse imaging. When, for control experiments $(n=10)$, nonspecific MITC-coupled immunoglobulins (IgGs) are introduced, the axons continue to grow after lipofection, as well as after laser treatment, without any alterations in their normal elongation rate $(3.0 \pm 0.2 \mu \mathrm{m} /$ $\mathrm{min}$ ) or in the morphology of their growth cones (Fig. 5a). The growth cones maintain their symmetric, fan-shaped form and neither the laser-treated side nor the untreated side show any significant $(p \leq$ 0.15 ) gain or loss in size (Fig. 6a). Moreover, the axons do not change the growth direction (Fig. 7a) but continue the steady elongation, performing only minor deflections to the left and right $\left(\leq 5^{\circ}\right)$, which is part of their normal "wandering" behavior (Fig. $7 d$ ). The control axons display only an extremely small, insignificant mean deviation angle $\left(+1.0 \pm 1.6^{\circ}\right.$; turns toward the laser-treated side: positive values; turns away: negative values) from the original direction after laser treatment (Fig. 7e). These experiments show that antibody lipofection and micro-CALI per se do not affect growth cone behavior or axon direction.

When antibodies directed against the $\mathrm{N}$ terminus of APC (APC-m) are introduced into the axons $(n=$ $10)$, the micro-CALI-treated side of the growth cone reacts immediately after the laser treatment (Fig. $5 b$ ). This growth cone side retracts substantially, with the most pronounced loss of area 4 min after onset of laser treatment (Fig. 6b). The untreated side, in contrast, forms protrusions and extends so that the overall growth cone size remains almost unchanged $(99.9 \pm 26 \%$ of the
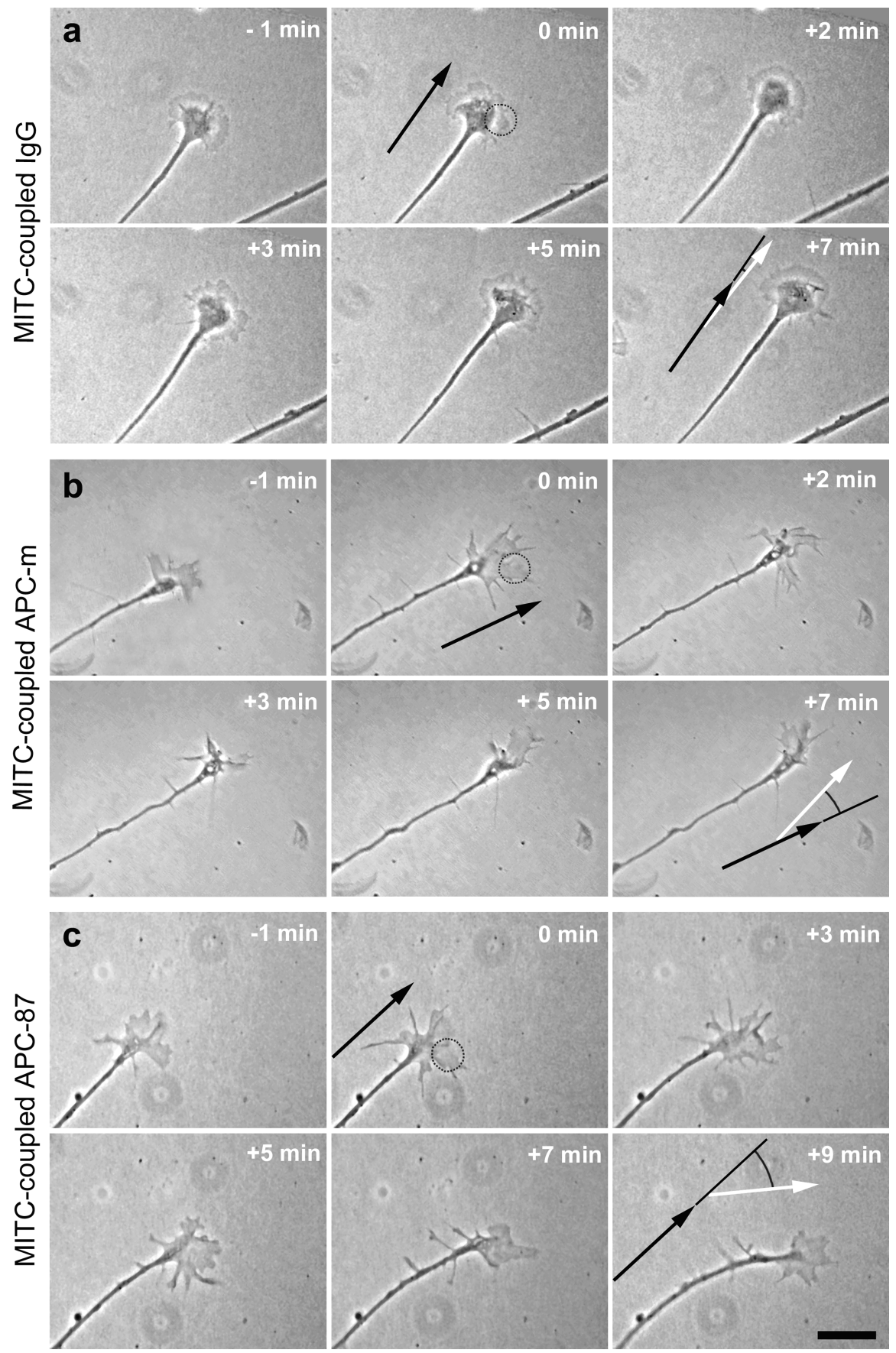

Figure 5. Axon and growth cone behavior after the local inactivation of APC domains. $\boldsymbol{a}$, Time-lapse phase-contrast micrographs show that the local inactivation of nonspecific IgGs (control experiments) by micro-CALI in one growth cone half of RGC axons extending from E6 retinal explants causes neither changes in growth cone morphology nor in axonal growth rate/direction. $\boldsymbol{b}$, Inactivation of the $\mathrm{N}$-terminal domain of APC in one growth cone half results in retraction of this growth cone region and a turn away from this side. $c$, In contrast, the inactivation of the 20 aa repeats in the middle domain of APC induces expansion of the laser-treated growth cone half and a turn toward this side. Dotted circles mark the position of the laser spot at the beginning of the irradiation period; because of the growth cone advance, the more rearward part of the growth cone half is also affected. The black and white arrows mark the growth direction before and after laser treatment, respectively. Scale bar, $25 \mu \mathrm{m}$.

area measured at $t=-1 \mathrm{~min})$; as a consequence, the growth cone becomes asymmetric with respect to the axis of the distalmost (10 $\mu \mathrm{m}$ ) axon (Fig. 6b). Subsequently, the axons turn away from the laser-treatedside (Fig. $7 b$ ); none of the axons turns toward and three showed only minor deflections, resulting in a highly significant mean turning angle of $-9.9 \pm 3.3^{\circ}(p \leq 0.002)$ (Fig. $7 d, e$ ).

In contrast, when antibodies directed against the seven 20 aa 

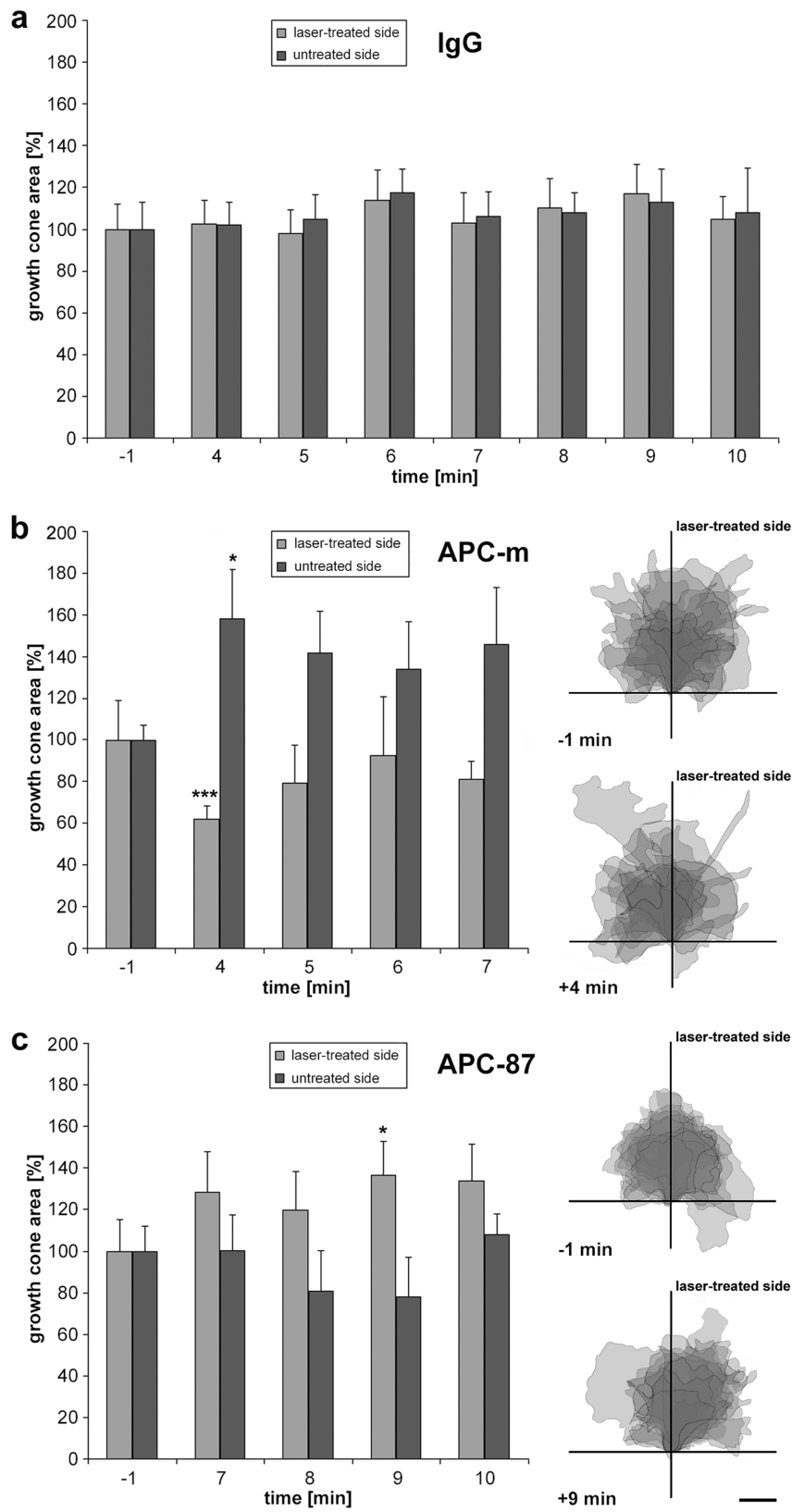

Figure 6. Differential growth cone reactions to the local inactivation of APC domains. $\boldsymbol{a}-\boldsymbol{c}$, Quantitative evaluation of growth cone changes after micro-CALI inactivation of nonspecific $\operatorname{lgGs}(\boldsymbol{a})$, of the $\mathrm{N}$-terminal domain of $\operatorname{APC}(\boldsymbol{b})$, and of the 20 aa repeats of $\operatorname{APC}(\boldsymbol{c} ; n=10$ each). Histograms show the increase and decrease in size of both growth cone halves with respect to the area covered by the halves before laser treatment, which is set to $100 \%$. Significant changes are marked by asterisks $\left({ }^{*} p \leq 0.05 ;{ }^{* * *} p \leq 0.001\right)$. Error bars indicate SEM. The same growth cones are represented as overlays of camera lucida drawings (each as semitransparency; darker shades indicating overlay of several growth cones) aligned by the position of the growth cone neck and the distal $10 \mu \mathrm{m}$ axon segment. Before laser treatment, growth cones exhibit a symmetric, approximately fan-shaped morphology. After irradiation, the growth cones acquire asymmetric forms, resulting in an overall shift away (b) or toward (c) the APC inactivation side. Scale bar, $10 \mu \mathrm{m}$.

repeats of APC (APC-87) are introduced into RGC axons $(n=$ $10)$, the micro-CALI-treated half of the growth cone expands (Fig. $5 c$ ). The gain of growth cone area is counterbalanced by a proportionate loss on the opposite side, causing an asymmetry in the growth cone morphology (Fig. 6c). This growth cone response (both expansion and shrinkage) is clearly slower than the one caused by micro-CALI using antibody APC-m reaching its maximum 9 min after onset of laser treatment; the overall growth cone size is again unchanged $(103.4 \pm 20 \%$ of the area at $t=-1$ min). Interestingly, the axons already start to turn toward the laser-treated side (three of them with only minor angles) before the growth cone response has reached its maximum. None of the axons turns away (Fig. $7 c$ ), resulting in a highly significant mean turning angle of $+13.9 \pm 4.4^{\circ}(p \leq 0.008)$ (Fig. $\left.7 d, e\right)$. To get first insight into the molecular interactions affected, micro-CALI via antibody APC-87 was applied in vitro to the peptide representing the third 20 aa repeat (supplemental Fig. 8, available at www. jneurosci.org as supplemental material). After peptide phosphorylation and incubation with $\beta$-catenin, a significant decrease of the bound $\beta$-catenin (fluorescence signal, $-4.3 \pm 0.7 \% ; p \leq$ $\left.10^{-8} ; n=15\right)$ is detected in the irradiation spot after 2 min laser treatment, revealing that binding of $\beta$-catenin to the 20 aa repeat is reduced by micro-CALI via antibody APC-87 (see Discussion).

Together, the selective inactivation of the APC N terminus, containing the crucial oligomerization region, and of the 20 aa repeats, capable of negatively regulating the APC-microtubule interaction, in one growth cone side causes opposite reactions, local collapse/turn away and local spreading/turn toward, respectively. This demonstrates the crucial role of the multifunctional and differentially distributed protein APC for the local regulation of growth cone dynamics and its impact on axonal navigation.

\section{Discussion \\ Spatiotemporal distribution of APC}

Our expression analysis reveals the changing levels of APC throughout development of the visual system: APC starts to be expressed with the beginning of RGC axon formation, indicating its importance for this cellular structure. Concomitant to axon elongation/maturation, APC becomes restricted to them and enriches at the growth cone, prerequisite for a role in axonal orientation. The distal axon contains the microtubule plus ends, and APC has been shown to accumulate at microtubule plus ends in non-neuronal cells (Mimori-Kiyosue et al., 2000; Kita et al., 2006). We moreover show that APC in distal axon and growth cone is extraction resistant, pointing to a strong association of APC to microtubules in this region and thus to a local microtubule protection by APC in this subdomain.

Within the growth cone, APC is predominately located in the microtubule-rich central growth cone domain, behind the most dynamic microtubules and in front of the more mature ones. The lack of APC-microtubule colocalization in the dorsal growth cone in contrast to the ventral, substrate-attached growth cone region, where most microtubules are APC decorated, could be caused by microtubules plus ends predominantly terminating at the ventral plasma membrane, as has been shown for epithelial cells (Mogensen et al., 2002), in which APC is present as a component of the ventral cortical network (Reilein and Nelson, 2005). We reasoned that this pointed to a more efficient accumulation of APC at microtubule plus ends slowing down/stopping at the plasma membrane than at growing ones because the peak velocity of APC along microtubules $(10 \mu \mathrm{m} / \mathrm{min})$ is considerably slower than the average microtubule growth rate $(18 \mu \mathrm{m} / \mathrm{min})$. To unequivocally discriminate growing from stopping microtubules, we thus used the marker EB3-GFP, which selectively binds to polymerizing microtubule plus ends. The release of EB3 is caused by microtubule depolymerization and diffuses away the head of the "EB3 comets," thus labeling specifically the tips of growing microtubules (Stepanova et al., 2003). We indeed found that APC is prominently accumulated only at those microtubule 
plus ends that terminate perpendicularly at the plasma membrane and are not decorated by EB3 (i.e., do not grow). In epithelial cells, APC has been shown to concentrate at growing microtubule ends and drop off as a result of depolymerization (Mimori-Kiyosue et al., 2000); these microtubules, however, were growing very slowly, extending toward the lamellar cell margin $(6 \mu \mathrm{m} / \mathrm{min})$, which could allow for APC accumulation at their plus ends.

In addition to numerous APC clusters at the microtubule tips, we also detected APC clusters at the plasma membrane independent of microtubules. Here APC might be linked to actin filaments of the cortical cytoskeleton via a complex with CLIP170 and IQGAP1 (see below) as found for the leading edge of nonneuronal cells (Watanabe et al., 2004; Noritake et al., 2005). This complex captures and protects microtubules; probably these processes also take place in the growth cone, thus contributing to its steering maneuvers. APC's capacity to support microtubule growth, bundling, and depolymerization resistance is well characterized for various non-neuronal cells; several lines of evidence exist that APC performs this function also in neurons (Zhou et al., 2004; Votin et al., 2005).

In steering growth cones, whether positively or negatively challenged, APC is always restricted to the maintained part of the growth cone (i.e., the region that is not retracted but consolidated); thus the local presence of APC predicts the future axonal growth direction. The directed transformation into axon requires local enhancement of microtubule extension and fasciculation; in this context, microtubule capture has been hypothesized to play a crucial role (Dent and Gertler, 2003; Gordon-Weeks, 2004; Kalil and Dent, 2005). The local presence of APC in the growth cone would make local enhancement of microtubule net growth possible, conceivably via the CLIP170/ IQGAP1 complex. Local recruitment of CLIP170, IQGAP1, and APC to cortical spots at leading edges in migrating cells has been proposed to be locally triggered by Cdc42/Racl (Fukata et al., 2002; Watanabe et al., 2004; Noritake et al., 2005), which is activated by integrins after ligand binding (Schoenwaelder and Burridge, 1999). We indeed see in growth cones at substrate borders the local accumulation of APC in the region on the highconcentrated laminin (an integrin ligand). Cdc42 was shown to locally activate $\mathrm{PKC} \zeta$, which inhibits GSK $3 \beta$ and thereby recruits APC to the microtubules (Etienne-Manneville and Hall, 2001, 2003), a prerequisite for local enhancement of the microtubulesupporting properties of APC; this could synergistically enhance the Cdc42/Rac1-induced protection of microtubules also in growth cones (see below).

\section{Function of APC in steering growth cones}

There is only a very limited number of studies shedding light on the function of APC in neurite tips/growth cones, mainly by (drug) inhibition of interaction partners or kinases (Morrison et al., 1997b; Zhou et al., 2004; Shimomura et al., 2005; Votin et al., 2005), together indicating a role of APC in microtubule organization/dynamics and the regulation of APC localization at microtubule ends by its phosphorylation status. We here present the first study targeting APC directly, locally, transiently, under physiological conditions, and at endogenous expression levels in proceeding growth cones by using micro-CALI. This is the only technique to allow for the study of intracellular proteins by acute and subunit-/domain-specific inactivation via short-lived hydroxyl radicals (Liao et al., 1995; Wang et al., 1996; Buchstaller and Jay, 2000; Wong and Jay, 2000; Eustace et al., 2002). Moreover, micro-CALI can specifically affect nonphosphorylated protein domains, depending on the binding specificity of the antibodies used, as has been used for studies on Tau and MAP1B (Liu et al., 1999; Mack et al., 2000).

For the micro-CALI studies, an antiserum raised against the first 20 aa repeat [APC-87 (Leroy et al., 2001)] was used, which selectively binds to APC in its unphosphorylated state. Our biochemical data (ELISA, dot blots, and peptide-micro-CALI) moreover demonstrate that antibody APC-87 binds with equal affinity not only to the first repeat but also to the one with the lowest similarity, the third, indicating that this antibody binds to 
all seven (highly homologous) 20 aa repeats. We could also show (by micro-CALI of the immobilized peptide) that micro-CALI via antibody APC-87 significantly reduces the binding of $\beta$-catenin to the third APC repeat. All 20 aa repeats bind $\beta$-catenin; the third is the one with the strongest $\beta$-catenin affinity (Liu et al., 2006). Thus, binding of $\beta$-catenin to all seven repeats has to be assumed to be reduced by micro-CALI with antibody APC- 87 . Diminished $\beta$-catenin binding to APC has been shown to reduce the integration of APC into the degradation complex, thereby promoting APC's binding to microtubules (Hart et al., 1998; Rubinfeld et al., 2001; Penman et al., 2005), which enhances microtubule elongation, bundling, net growth, and resistance against depolymerization, as has been shown for non-neuronal cells (Näthke, 2004). The steric alterations in the 20 aa repeats caused by micro-CALI affect the binding sites for $\beta$-catenin and/or GSK $3 \beta$, both resulting in diminished $\beta$-catenin binding, because GSK $3 \beta$ phosphorylation of APC is a prerequisite for effective $\beta$-catenin binding. Lack of GSK3 $\beta$ phosphorylation promotes binding of APC to microtubules and prevents the APC dissociation from the microtubules, resulting in increased microtubule elongation and bundling (Zumbrunn et al., 2001; Näthke, 2004; Etienne-Manneville et al., 2005). We indeed observe a pronounced expansion of the micro-CALI-treated growth cone side, which is a hallmark for enhanced microtubule net growth (Buck and Zheng, 2002), indicating that the inactivation of the 20 aa repeats leads to differential molecular, yet synergistic cellular effects that together result in local microtubule support causing a positive turn.

Micro-CALI via an antibody directed against the $\mathrm{N}$-terminal 250 aa (APC-m) inactivates the APC oligomerization domain, which is crucial for its dimerization (Joslyn et al., 1993; Day and Alber, 2000). Conceivably, micro-CALI inactivation not only prevents the dimerization but might also weaken already-formed dimers as APC-m antibodies bind (beyond the parallel, helical coiled-coil dimerization domain proper) also to the adjacent region, in which the two APC helices splay apart and thus are sterically more accessible for antibody binding (Day and Alber, 2000; Tickenbrock et al., 2002). Studies in non-neuronal cells showed that APC is present at microtubule crossing points (Reilein and Nelson, 2005) and within microtubule bundles (Mimori-Kiyosue et al., 2000), suggesting that APC might act as a microtubule cross-linker, with its dimerization as a prerequisite. MicroCALI using APC-m antibodies hence conceivably abolishes these microtubule-organizing functions of APC, causing disintegration of microtubule bundles/networks, triggering retraction of the treated growth cone side. Loss of APC (by RNAi) has been shown to result in protrusion reduction in non-neuronal cells, whereas overexpression leads to long, microtubule-filled protrusions (Kroboth et al., 2007). Our experiments show a novel role of the $\mathrm{N}$-terminal 250 aa region beyond the shuttle function of the nuclear export signals located in this region (Henderson, 2000; Tickenbrock et al., 2002) and furthermore demonstrate that this APC region plays an important role in axon navigation.

\section{References}

Avci HX, Zelina P, Thelen K, Pollerberg GE (2004) Role of cell adhesion molecule DM-GRASP in growth and orientation of retinal ganglion cell axons. Dev Biol 271:291-305.

Baas PW, Karabay A, Qiang L (2005) Microtubules cut and run. Trends Cell Biol 15:518-524.

Beermann AE, Jay DG (1994) Chromophore-assisted laser inactivation of cellular proteins. Methods Cell Biol 44:715-732.
Bhat RV, Baraban JM, Johnson RC, Eipper BA, Mains RE (1994) High levels of expression of the tumor suppressor gene APC during development of the rat central nervous system. J Neurosci 14:3059-3071.

Black MM, Slaughter T, Fischer I (1994) Microtubule-associated protein 1b (MAP1b) is concentrated in the distal region of growing axons. J Neurosci 14:857-870.

Buchstaller A, Jay DG (2000) Micro-scale chromophore-assisted laser inactivation of nerve growth cone proteins. Microsc Res Tech 48:97-106.

Buck KB, Zheng JQ (2002) Growth cone turning induced by direct local modification of microtubule dynamics. J Neurosci 22:9358-9367.

Day CL, Alber T (2000) Crystal structure of the amino-terminal coiled-coil domain of the APC tumor suppressor. J Mol Biol 301:147-156.

Deka J, Kuhlmann J, Müller O (1998) A domain within the tumor suppressor protein APC shows very similar biochemical properties as the microtubule-associated protein tau. Eur J Biochem 253:591-597.

Dent EW, Gertler FB (2003) Cytoskeletal dynamics and transport in growth cone motility and axon guidance. Neuron 40:209-227.

Diefenbach TJ, Latham VM, Yimlamai D, Liu CA, Herman IM, Jay DG (2002) Myosin 1c and myosin IIB serve opposing roles in lamellipodial dynamics of the neuronal growth cone. J Cell Biol 158:1207-1217.

Dobashi Y, Bhattacharjee RN, Toyoshima K, Akiyama T (1996) Upregulation of the APC gene product during neuronal differentiation of rat pheochromocytoma PC12 cells. Biochem Biophys Res Commun 224:479-483.

Dobashi Y, Katayama K, Kawai M, Akiyama T, Kameya T (2000) APC protein is required for initiation of neuronal differentiation in rat pheochromocytoma PC12 cells. Biochem Biophys Res Commun 279:685-691.

Etienne-Manneville S, Hall A (2001) Integrin-mediated activation of Cdc42 controls cell polarity in migrating astrocytes through PKCzeta. Cell 106:489-498.

Etienne-Manneville S, Hall A (2003) Cdc42 regulates GSK-3beta and adenomatous polyposis coli to control cell polarity. Nature 421:753-756.

Etienne-Manneville S, Manneville JB, Nicholls S, Ferenczi MA, Hall A (2005) Cdc42 and Par6-PKCzeta regulate the spatially localized association of Dlg1 and APC to control cell polarization. J Cell Biol 170:895-901.

Eustace BK, Buchstaller A, Jay DG (2002) Adapting chromophore-assisted laser inactivation for high throughput functional proteomics. Brief Funct Genomic Proteomic 1:257-265.

Fukata M, Watanabe T, Noritake J, Nakagawa M, Yamaga M, Kuroda S, Matsuura Y, Iwamatsu A, Perez F, Kaibuchi K (2002) Racl and Cdc42 capture microtubules through IQGAP1 and CLIP-170. Cell 109:873-885.

Gordon-Weeks PR (2004) Microtubules and growth cone function. J Neurobiol 58:70-83.

Groden J, Thliveris A, Samowitz W, Carlson M, Gelbert L, Albertsen H, Joslyn G, Stevens J, Spirio L, Robertson M, Sargeant L, Krapcho K, Wolff E, Burt R, Hughes JP, Warrington J, McPherson J, Wasmuth J, Le Paslier D, et al. (1991) Identification and characterization of the familial adenomatous polyposis coli gene. Cell 66:589-600.

Haegele L, Ingold B, Naumann H, Tabatabai G, Ledermann B, Brandner S (2003) Wnt signalling inhibits neural differentiation of embryonic stem cells by controlling bone morphogenetic protein expression. Mol Cell Neurosci 24:696-708.

Hahn CM, Kleinholz H, Koester MP, Grieser S, Thelen K, Pollerberg GE (2005) Role of cyclin-dependent kinase 5 and its activator P35 in local axon and growth cone stabilization. Neuroscience 134:449-465.

Hanson CA, Miller JR (2005) Non-traditional roles for the Adenomatous Polyposis Coli (APC) tumor suppressor protein. Gene 361:1-12.

Hart MJ, de los Santos R, Albert IN, Rubinfeld B, Polakis P (1998) Downregulation of beta-catenin by human Axin and its association with the APC tumor suppressor, beta-catenin and GSK3 beta. Curr Biol 8:573-581.

Hasegawa S, Sato T, Akazawa H, Okada H, Maeno A, Ito M, Sugitani Y, Shibata H, Miyazaki J, Katsuki M, Yamauchi Y, Yamamura K, Katamine S, Noda T (2002) Apoptosis in neural crest cells by functional loss of APC tumor suppressor gene. Proc Natl Acad Sci USA 99:297-302.

Henderson BR (2000) Nuclear-cytoplasmic shuttling of APC regulates beta-catenin subcellular localization and turnover. Nat Cell Biol 2:653-660.

Joslyn G, Richardson DS, White R, Alber T (1993) Dimer formation by an $\mathrm{N}$-terminal coiled coil in the APC protein. Proc Natl Acad Sci USA 90:11109-11113. 
Kalil K, Dent EW (2005) Touch and go: guidance cues signal to the growth cone cytoskeleton. Curr Opin Neurobiol 15:521-526.

Kita K, Wittmann T, Näthke IS, Waterman-Storer CM (2006) Adenomatous polyposis coli on microtubule plus ends in cell extensions can promote microtubule net growth with or without EB1. Mol Biol Cell 17:2331-2345.

Kroboth K, Newton IP, Kita K, Dikovskaya D, Zumbrunn J, WatermanStorer CM, Näthke IS (2007) Lack of adenomatous polyposis coli protein correlates with a decrease in cell migration and overall changes in microtubule stability. Mol Biol Cell 18:910-918.

Leroy K, Duyckaerts C, Bovekamp L, Müller O, Anderton BH, Brion JP (2001) Increase of adenomatous polyposis coli immunoreactivity is a marker of reactive astrocytes in Alzheimer's disease and in other pathological conditions. Acta Neuropathol (Berl) 102:1-10.

Liao JC, Roider J, Jay DG (1994) Chromophore-assisted laser inactivation of proteins is mediated by the photogeneration of free radicals. Proc Natl Acad Sci USA 91:2659-2663.

Liao JC, Berg LJ, Jay DG (1995) Chromophore-assisted laser inactivation of subunits of the T-cell receptor in living cells is spatially restricted. Photochem Photobiol 62:923-929.

Linden KG, Liao JC, Jay DG (1992) Spatial specificity of chromophore assisted laser inactivation of protein function. Biophys J 61:956-962.

Liu CW, Lee G, Jay DG (1999) Tau is required for neurite outgrowth and growth cone motility of chick sensory neurons. Cell Motil Cytoskeleton 43:232-242.

Liu J, Xing Y, Hinds TR, Zheng J, Xu W (2006) The third 20 amino acid repeat is the tightest binding site of APC for beta-catenin. J Mol Biol 360:133-144.

Mack TG, Koester MP, Pollerberg GE (2000) The microtubule-associated protein MAP1B is involved in local stabilization of turning growth cones. Mol Cell Neurosci 15:51-65.

Matsumine A, Ogai A, Senda T, Okumura N, Satoh K, Baeg GH, Kawahara T, Kobayashi S, Okada M, Toyoshima K, Akiyama T (1996) Binding of APC to the human homolog of the Drosophila discs large tumor suppressor protein. Science 272:1020-1023.

Mimori-Kiyosue Y, Shiina N, Tsukita S (2000) Adenomatous polyposis coli (APC) protein moves along microtubules and concentrates at their growing ends in epithelial cells. J Cell Biol 148:505-518.

Mogensen MM, Tucker JB, Mackie JB, Prescott AR, Näthke IS (2002) The adenomatous polyposis coli protein unambiguously localizes to microtubule plus ends and is involved in establishing parallel arrays of microtubule bundles in highly polarized epithelial cells. J Cell Biol 157:1041-1048.

Morrison EE, Askham JM, Clissold P, Markham AF, Meredith DM (1997a) The cellular distribution of the adenomatous polyposis coli tumour suppressor protein in neuroblastoma cells is regulated by microtubule dynamics. Neuroscience 81:553-563.

Morrison EE, Askham J, Clissold P, Markham AF, Meredith DM (1997b) Expression of beta-catenin and the adenomatous polyposis coli tumour suppressor protein in mouse neocortical cells in vitro. Neurosci Lett 235:129-132.

Munemitsu S, Souza B, Müller O, Albert I, Rubinfeld B, Polakis P (1994) The APC gene product associates with microtubules in vivo and promotes their assembly in vitro. Cancer Res 54:3676-3681.

Nakamura M, Zhou XZ, Lu KP (2001) Critical role for the EB1 and APC interaction in the regulation of microtubule polymerization. Curr Biol 11:1062-1067.

Näthke IS (2004) The adenomatous polyposis coli protein: the Achilles heel of the gut epithelium. Annu Rev Cell Dev Biol 20:337-366.

Noritake J, Watanabe T, Sato K, Wang S, Kaibuchi K (2005) IQGAP1: a key regulator of adhesion and migration. J Cell Sci 118:2085-2092.

Penman GA, Leung L, Näthke IS (2005) The adenomatous polyposis coli protein (APC) exists in two distinct soluble complexes with different functions. J Cell Sci 118:4741-4750.
Pollerberg GE, Beck-Sickinger A (1993) A functional role for the middle extracellular region of the neural cell adhesion molecule (NCAM) in axonal fasciculation and orientation. Dev Biol 156:324-340.

Pollerberg GE, Mack TG (1994) Cell adhesion molecule SC1/DMGRASP is expressed on growing axons of retina ganglion cells and is involved in mediating their extension on axons. Dev Biol 165:670-687.

Pollerberg GE, Sadoul R, Goridis C, Schachner M (1985) Selective expression of the $180-\mathrm{kD}$ component of the neural cell adhesion molecule N-CAM during development. J Cell Biol 101:1921-1929.

Reilein A, Nelson WJ (2005) APC is a component of an organizing template for cortical microtubule networks. Nat Cell Biol 7:463-473.

Rubinfeld B, Albert I, Porfiri E, Fiol C, Munemitsu S, Polakis P (1996) Binding of GSK3beta to the APC-beta-catenin complex and regulation of complex assembly. Science 272:1023-1026.

Rubinfeld B, Tice DA, Polakis P (2001) Axin-dependent phosphorylation of the adenomatous polyposis coli protein mediated by casein kinase lepsilon. J Biol Chem 276:39037-39045.

Schoenwaelder SM, Burridge K (1999) Bidirectional signaling between the cytoskeleton and integrins. Curr Opin Cell Biol 11:274-286.

Shi SH, Cheng T, Jan LY, Jan YN (2004) APC and GSK-3beta are involved in mPar3 targeting to the nascent axon and establishment of neuronal polarity. Curr Biol 14:2025-2032.

Shimomura A, Kohu K, Akiyama T, Senda T (2005) Subcellular localization of the tumor suppressor protein APC in developing cultured neurons. Neurosci Lett 375:81-86.

Stepanova T, Slemmer J, Hoogenraad CC, Lansbergen G, Dortland B, De Zeeuw CI, Grosveld F, van Cappellen G, Akhmanova A, Galjart N (2003) Visualization of microtubule growth in cultured neurons via the use of EB3-GFP (end-binding protein 3-green fluorescent protein). J Neurosci 23:2655-2664.

Temburni MK, Rosenberg MM, Pathak N, McConnell R, Jacob MH (2004) Neuronal nicotinic synapse assembly requires the adenomatous polyposis coli tumor suppressor protein. J Neurosci 24:6776-6784.

Thanos S, Mey J (2001) Development of the visual system of the chick. II. Mechanisms of axonal guidance. Brain Res Brain Res Rev 35:205-245.

Tickenbrock L, Cramer J, Vetter IR, Müller O (2002) The coiled coil region (amino acids 129-250) of the tumor suppressor protein adenomatous polyposis coli (APC). Its structure and its interaction with chromosome maintenance region 1 (Crm-1). J Biol Chem 277:32332-32338.

Votin V, Nelson WJ, Barth AI (2005) Neurite outgrowth involves adenomatous polyposis coli protein and \{beta\}-catenin. J Cell Sci 118:5699-5708.

Wang FS, Liu CW, Diefenbach TJ, Jay DG (2003) Modeling the role of myosin 1c in neuronal growth cone turning. Biophys J 85:3319-3328.

Wang FS, Wolenski JS, Cheney RE, Mooseker MS, Jay DG (1996) Function of myosin- $\mathrm{V}$ in filopodial extension of neuronal growth cones. Science 273:660-663.

Watanabe T, Wang S, Noritake J, Sato K, Fukata M, Takefuji M, Nakagawa M, Izumi N, Akiyama T, Kaibuchi K (2004) Interaction with IQGAP1 links APC to Rac1, Cdc42, and actin filaments during cell polarization and migration. Dev Cell 7:871-883.

Wong EV, Jay DG (2000) Study of in situ function of cytoskeletal proteins in lamellipodia and filopodia using microscale chromophore-assisted laser inactivation. Methods Enzymol 325:482-496.

Zelina P, Avci HX, Thelen K, Pollerberg GE (2005) The cell adhesion molecule NrCAM is crucial for growth cone behaviour and pathfinding of retinal ganglion cell axons. Development 132:3609-3618.

Zhou FQ, Zhou J, Dedhar S, Wu YH, Snider WD (2004) NGF-induced axon growth is mediated by localized inactivation of GSK-3beta and functions of the microtubule plus end binding protein APC. Neuron 42:897-912.

Zumbrunn J, Kinoshita K, Hyman AA, Näthke IS (2001) Binding of the adenomatous polyposis coli protein to microtubules increases microtubule stability and is regulated by GSK3 beta phosphorylation. Curr Biol 11:44-49. 